\title{
Children skilled in mental abacus show enhanced non-symbolic number sense
}

Jiaxin Cui ${ }^{1,2,3}$, Rui Xiao ${ }^{1,2,3}$, Mei Ma ${ }^{1,2,3}$, Li Yuan ${ }^{1,2,3}$, Roi Cohen Kodash ${ }^{4}$, Xinlin Zhou $^{1,2,3}$

${ }^{1}$ State Key Laboratory of Cognitive Neuroscience, Learning \& IDG/McGovern Institute for Brain Research, Beijing Normal University, Beijing, China, 100875.

${ }^{2}$ Advanced Innovation Center for Future Education, Beijing Normal University, Beijing, China, 100875.

${ }^{3}$ Siegler Center for Innovative Learning, Beijing Normal University, Beijing, China, 100875.

${ }^{4}$ Department of Experimental Psychology, University of Oxford, Oxford, UK.

Jiaxin Cui and Rui Xiao contributed equally to this work.

Correspondence: Xinlin Zhou, State Key Laboratory of Cognitive Neuroscience and Learning \& IDG/McGovern Institute for Brain Research Center for Collaboration and Innovation in Brain and Learning Sciences, Beijing Normal University, Beijing, China, 100875. Email address: zhou_xinlin@bnu.edu.cn. 


\section{Highlights}

1) No studies have shown the advantage of non-symbolic number sense for children skilled in mental abacus.

2) Children skilled in mental abacus had better non-symbolic number sense than the controls after controlling for age, gender, general cognitive processing and even arithmetic performance.

3) A mediation model showed that the non-symbolic number sense partially mediated group difference (mental abacus group vs. controls) in symbolic arithmetic. 


\begin{abstract}
Mental abacus is the mental arithmetic with the help of an imagined abacus. Children skilled in mental abacus have been shown to exhibit advantages in arithmetic abilities. The current study investigated whether children with high-level mental abacus ability could outperform controls in non-symbolic number sense, which is considered to be much fundamental for arithmetic development. One hundred and fifty children (75 children skilled in mental abacus and 75 controls) took part in this study. Children skilled in mental abacus completed a mental abacus level test. Two groups of children performed serial cognitive tasks, including non-symbolic number comparison, arithmetic, language, spatial processing, visual perception, attention, processing speed, working memory, and general intelligence. Results show that children skilled in mental abacus had better non-symbolic number sense than the controls after controlling for general intelligence. The significant group difference of non-symbolic number sense retained after further controlling for age, gender, all types of cognitive processing available and even arithmetic performance. A mediation model showed that the non-symbolic number sense partially mediated the group difference on arithmetic development. The results suggest that children skilled in mental abacus have enhanced non-symbolic number sense. These findings raise the possibility that mental abacus training could have a causal effect on children's non-symbolic numerical skills.
\end{abstract}

Keywords: Mental abacus, Non-symbolic number sense, Cognitive arithmetic, Numerical processing, Mathematical cognition 


\section{Introduction}

The Chinese abacus is an arithmetic device that was invented in China more than 800 years ago (Li, Chen, \& Huang, 2016). It was widely utilized in medieval to premodern East Asia for rapid exact calculation (Menninger, 1969), but due to the advent of electronic products for calculation, such as calculators and computers, has stopped being used in professional work that require arithmetic. Instead, the abacus has been transformed into an educational tool to promote arithmetic ability in children.

Additionally, some children can acquire the ability of performing abacus calculation in their minds, which is called mental abacus. In December 2013, reckoning by the abacus was formally listed into the directory of human intangible cultural heritage by the United Nations Educational, Scientific, and Cultural Organization (UNESCO). As of December 2016, 76 countries and regions have popularized the education with the abacus and mental abacus (Meng, 2016, in Chinese version).

The abacus represents numbers via positions of beads aligned in columns, with each column representing a place value, increasing from right to left, and with each "earth" bead representing " 1 " and each "heaven" bead representing for " 5 " (as shown in Figure 1, also see Chalip \& Stigler, 1986; Hatano, Miyake, \& Binks, 1977; Hatano \& Osawa, 1983; Hishitani, 1990; Miller \& Stigler, 1991; Stigler, 1984).

During mental abacus training, students are first trained to calculate using a physical abacus with their fingers. Then, they are instructed to imagine operating beads on a mental abacus, but to use actual finger movements in the air. Finally, they can perform mental calculations completely in their minds using the imaged abacus- 
imagining the beads moving in an orderly spatial alignment — with or without visible finger movements (Du et al., 2013; Frank \& Barner, 2012).

Studies consistently show that children skilled in mental abacus have better arithmetic ability than those who did not receive mental abacus training (Amaiwa \& Hatano, 1989; Barner et al., 2016; Chen et al., 2006; Donlan \& Wu, 2017; Hanakawa, Honda, Okada, Fukuyama, \& Shibasaki, 2003; Huang et al., 2015; Ku, Hong, Zhou, Bodner, \& Zhou, 2012; Na, Lee, Park, Jung, \& Ryu, 2015; Shen, 1999; Stigler, 1984; Wang et al., 2015; Wu et al., 2009). The arithmetic advantage from mental abacus training could be due to the implement of skilled mental abacus (e.g., Barner et al., 2016; Barner et al., 2018; Shen, 2006) or the familiarity of the numbers, arithmetic facts and procedures (e.g., Amaiwa \& Hatano, 1989; Donlan \& Wu, 2017; Rau, Xie, $\mathrm{Li}, \&$ Chen, 2015). The arithmetic advantage actually is the advantage of the symbolic number system. Little knowledge is about the advantage of training mental abacus in the non-symbolic number system, which is typically claimed as one of foundations for the arithmetic development (e.g., Cui et al., 2019; Halberda et al., 2008).

To our best knowledge, there have been 2 studies to investigate the effect of training mental abacus on the non-symbolic number system (Barner, Alvarez, Sullivan, Brooks, Srinivasan \& Frank, 2016; Sullivan, Frank, \& Barner, 2016). Neither Barner et al. (2016) or Sullivan et al. (2016) has found significant difference in Weber fraction of non-symbolic number processing between mental abacus group and control group of Indian children from low-income families after training for three years (from Grade 2 to Grade 4, two 90-minute lessons per week). However, we could 
not ensure whether children from the two studies were skilled in mental abacus. The mental abacus levels of the children have not been assessed.

After effective training, it is hypothesized that the non-symbolic number system can be improved. First, the abacus actually is to perform computation based on nonsymbolic number. During training, learners should first transform the symbolic numbers (typically Arabic digits) into the non-symbolic number in physical abacus or mental abacus, then perform the computation following the rules of moving beads, and finally transform the non-symbolic number into symbolic number. Second, mental abacus training would result in better arithmetic performance (Amaiwa \& Hatano, 1989; Barner et al., 2016; Chen et al., 2006; Donlan \& Wu, 2017; Hanakawa, Honda, Okada, Fukuyama, \& Shibasaki, 2003; Huang et al., 2015; Ku, Hong, Zhou, Bodner, \& Zhou, 2012; Na, Lee, Park, Jung, \& Ryu, 2015; Shen, 1999; Stigler, 1984; Wang et al., 2015; Wu et al., 2009), which typically has been shown to be associated with the non-symbolic number sense (e.g., Cui et al., 2019; Halberda et al., 2008; Zhou et al., 2015).

The current study aimed at investigating the advantage of non-symbolic number system after mental abacus training. The children skilled in mental abacus would be compared to the children who did not receive any mental abacus training. The nonsymbolic number sense is a typical number ability in the non-symbolic number system. It has been received much attention in previous studies. Studies showed the close association between the non-symbolic number sense and some of measures for mathematics (e.g., Cui et al., 2019; Halberda et al., 2008; Zhang et al., 2016; Zhou et 
al., 2015; Zhou \& Cheng, 2015).

Following the basic hypothesis that the non-symbolic number sense can be improved after mental abacus training, it was expected that the non-symbolic number sense could be better for children skilled in mental abacus by comparison with those who did not have the training.

To examine if there is substantial group difference between children skilled in mental abacus and their peers on non-symbolic number sense, some important cognitive factors would be controlled. The factors included general intelligence (Cowan \& Powell, 2014; Fuchs, Fuchs, Compton, Hamlett, \& Wang, 2015; Jordan et al., 2013), visuospatial processing ability (Boonen, van Wesel, Jolles, \& van der Schoot, 2014; Kyttala et al., 2014; Looi et al., 2017; Swanson, Jerman, \& Zheng, 2009), processing speed (Berg, 2008; Bull \& Johnston, 1997; Fuchs et al., 2006), and language processing (Hecht, Torgesen, Wagner, \& Rashotte, 2001; Purpura \& Ganley, 2014; Wei, Yuan, Chen, \& Zhou, 2012). It is to ensure that group difference in approximate number sense originates from mental abacus experience rather than outperformances of the cognitive factors.

\section{Methods}

\section{Participants}

A total of 150 Chinese children in grades $2-6$ (92 boys and 58 girls; mean age $=$ 107.2 months; $\mathrm{SD}=12.5$, age range: 87 to 133 months) participated in the current study. We recruited 75 children who reached at least Level 6 on the Standard Mental Abacus Test laid down by the Chinese association of Abacus and Mental Calculation 
(Ni, 2007, in Chinese version). The detailed descriptions of the arithmetic questions for each level were shown in Appendix 1. Specifically, Level 6 requires mental abacus learners to obtain at least 8/10 correct answers within 300 seconds by mental calculation. Each arithmetic problem in Level 6 has 7 integers as operands, including 1 three-digit integer, 3 two-digit integers and 3 one-digit integers (for example, “69+ $258+47+25+2+8+3$ ". Each participant in mental abacus group had a matched control who had no any formal mental abacus training. That is, they came from same school with same gender, grade and age (within a month)Thus, the controls were also 75 children.

Children were recruited from a public suburban primary school in Beijing and from five private inner-city educational services in Beijing, Handan, and Jiamusi, serving children from diverse socioeconomic backgrounds. The children were all formally educated following the national curriculum, while mental abacus experts had studied mental abacus as an extracurricular interest and their peers had other types of hobbies (e.g., music and calligraphy). All children were native Mandarin speakers, with normal or corrected-to-normal vision. None of the children were diagnosed with any intellectual, behavioral, sensory, or neurological deficits. Parental written consent was obtained prior to testing.

\section{Tests}

We used 11 tests that were designed with the "Online Psychological Experiment System (OPES)" (www.dweipsy.com/lattice, see (Cui, Zhang, Cheng, Li, \& Zhou, 2017; Wei, Chen, Dong, \& Zhou, 2016; Wei et al., 2012; Zhou \& Cheng, 2015; Zhou 
et al., 2015). An illustration of a trial for each test is shown in Figure 2.

1. Mental abacus level test. This test assessed the mental abacus ability of the mental abacus experts, but not of the control students because would be too difficult for people without special mental abacus training. The evaluation was based on the rules for abacus and mental arithmetic laid down by the Chinese Association of Abacus and Mental Calculation (Ni, 2007, in Chinese version). The test was divided into 10 levels (10 being the highest), with each level having 10 arithmetic problems (addition, subtraction, or a combination) that included both integers and decimal numbers. A detailed description of each level is provided in Appendix 1. Mental abacus experts were required to enter their answers to these arithmetic problems using a keyboard. They had 5 minutes for each level and could pass a level if they answered at least 8 of the problems correctly. The number of correct trials was used as the score for each level, and the total score was calculated as the weighted sum of these score across all levels. That is, total score $=1 \times N_{10}+2 \times N_{9}+3 \times N_{8}+4 \times N_{7}+5 \times N_{6}+6 \times N_{5}+7$ $\times N_{4}+8 \times N_{3}+9 \times N_{2}+10 \times N_{1} . N_{i}$ is the number of corrected answers in the $i^{\text {th }}$ level.

2. Subtraction test. This task was used to test arithmetic fluency (Cui et al., 2017; Wei et al., 2012; Zhou et al., 2015). For each trial, a simple-subtraction problem (e.g., 6 $2,17-8$ ) was presented in the center of the screen, with minuends no more than 18 , and answers as single-digit numbers. Beneath each problem, two choices were presented. Participants were asked to press the "Q" key to select the answer on the left and the "P" key to select the answer on the right. Each incorrect choice was within 3 
of the correct answer (i.e., $\pm 1, \pm 2$, or \pm 3 ). The test had 92 trials, and children were allotted 2 minutes to complete as many of the problems as accurately as possible.

An adjusted number of correct trials was used to control for the effect of guessing in multiple choice tests (Cirino, 2011; Hedden \& Yoon, 2006; Salthouse \& Coon, 1994; Salthouse \& Meinz, 1995). The score was calculated by subtracting the number of incorrect responses from the number of correct responses following the Guilford correction formula: "S $=(\mathrm{R}-\mathrm{W}) /(\mathrm{n}-1)$ " ( $\mathrm{S}$ : the adjusted number of items that the participants can actually perform without the aid of chance; $\mathrm{R}$ : the number of correct responses; W: the number of incorrect responses; $\mathrm{n}$ : the number of alternative responses to each item) (Guilford \& Guilford, 1936). This correction procedure has been utilized recently in studies of mathematical cognition (Cirino, 2011; Wei et al., 2012; Zhou et al., 2015) and cognition in general (Hedden \& Yoon, 2006; Putz, Gaulin, Sporter, \& McBurney, 2004; Salthouse \& Coon, 1994).

3. Numerosity comparison. This test was used to assess non-symbolic number sense (Cui et al., 2017; Wei et al., 2012; Zhou et al., 2015). In each trial, two dot arrays appeared simultaneously on the screen, lasting for $200 \mathrm{~ms}$. Participants were asked to judge which dot array contained more dots by pressing 'Q' to choose the left array or ' $\mathrm{P}$ ' to choose the right array, while ignoring all visual properties such as total surface area, envelope area, diameter, or circumference. The interval between the response and the onset of the next trial was $1,000 \mathrm{~ms}$. The test comprised 120 trials and was administered in three 40-trial sessions. 
The dot arrays were created following a common procedure to minimize the effect that continuous non-numerical quantities have on non-symbolic numerical discrimination (Agrillo, Piffer, \& Adriano, 2013; Halberda, Mazzocco, \& Feigenson, 2008). For half the trials, the two arrays had the same total combined area, and for the other half, they had the same average area for all dots. Each dot array included 11, 14, $17,20,23,26$, or 29 dots, presented in gray circles that had a visual angle of $6.8^{\circ}$. The two dot arrays were horizontally aligned and extended to a combined visual angle of about $14^{\circ}$. The ratio of dots between the two arrays ranged from 1.2 to 2.0. The dots were randomly distributed within the gray circle and the sizes varied. The envelope area/convex hull varied little from trial to trial.

Gebuis and Reynvoet (2011) proposed that five visual properties of the numerosity comparison task could affect numerosity comparison: total surface area, envelope area or convex hull, item size, density, and circumference. Density is defined as the number of items per unit area (Anobile, Stievano, \& Burr, 2013; Tinelli et al., 2015). Zhou et al. (2015) showed that the numerosity comparison task was still ratio-dependent after these five visual properties were controlled. To confirm this finding, the current investigation also examined the effects of visual properties on task performance.

Median reaction time (only for correct responses) and accuracy (percentage of correct trials) were used as indices.

4. Figure matching. This test was used to assess ability in visual form perception, and was adapted from Ekstrom's identical picture test in the Manual for the Kit of Factor- 
Referenced Cognitive Tests (Ekstrom, French, Harman, \& Dermen, 1976). For each trial, two sets of complex figures were presented simultaneously on the screen, lasting for $400 \mathrm{~ms}$. The left set contained only one figure, and the right set contained three figures. Each figure was a combination of two simple line shapes randomly selected from an array of 150 simple line shapes. Participants were asked to judge whether the left figure matched any of the right figures by pressing the "Q" and "P" keys on the keyboard for "yes" and "no", respectively. The test comprised 120 trials, which were grouped into three 40-trial sessions. Median reaction time and accuracy (percentage of correct trials) were used as indices.

5. Visual searching. This test was used to assess attentional ability. For each trial, a line of 5-8 items were simultaneously presented at the center of the screen until the students responded. Each figure was a combination of two shapes randomly selected from an array of 150 simple line shapes. Participants were asked to press the "P" key if any of the figures comprised a square and a circle and the "Q" key if they did not. The test comprised 240 trials and was limited to 4 minutes. The adjusted number of correct trials was used as the index.

6. Three-dimensional mental rotation. This test was used to assess spatial processing ability, and was adapted from Shepard and Metzler's mental rotation task (Shepard \& Metzler, 1971). In each trial, a 3-D figure was presented at the top of the screen along with side-by-side rotated $\left(15^{\circ}\right.$ to $\left.345^{\circ}\right)$ and mirror-image versions beneath. Participants were asked to judge which of the lower images was the same as the top image (i.e., the rotated version) by pressing appointed keys on the keyboard. This test 
included 180 trials and was limited to 3 minutes. The adjusted number of correct trials was used as the index.

7. Spatial working memory. This task was similar to the Corsi block task (Corsi, 1972) and has been used in previous studies (Cui et al., 2017; Zhou et al., 2015). Dots were sequentially presented in an implicit $3 \times 3$ lattice of on the computer screen. Each dot lasted $1,000 \mathrm{~ms}$, and the interval between dot presentations was also 1,000 ms. After the last dot had been presented and disappeared, the participants used the computer mouse to click the positions where the dots had appeared in the same sequence as their appearance. The number of dots ranged from 4 to 9 . There was no feedback to participants. The average distance between the positions where the dots appeared and the positions where participants clicked was calculated and treated as an index of spatial working memory. Larger average distances reflect poorer spatial working memory. The score of this test was calculated as accuracy, using the following formula: Accuracy $=100-\mid$ response - standard answer $\mid /($ standard answer $+\mid$ response - standard answer $\mid) \times 100$. The formula returns values from 0 to 100 . 'Response' refers to the participants' answers, and 'standard answer' refers to the correct answer. Deviation of a participant's answer from the standard answer is divided by the sum of the standard answer and the deviation, which gives the degree of deviation from the standard value.

8. Verbal working memory. This test was taken from the digit-span task of the Wechsler Adult Intelligence Scale (WAIS - III: Wechsler, 1997). In each trial, several digits were audibly presented with frequency of one digit per second. Participants 
were asked to remember these digits and write them down in the same (forward position) or opposite (backward condition) sequence as they were presented. The number of digits began at three, and would either increase by one if participants made a correct answer or remain the same length. The test stopped when participants gave 3 consecutive incorrect answers. The number of digits in this final string was used as their score.

9. Nonverbal matrix reasoning. This test was adapted from Raven's Progressive Matrices (Raven, 2000) to assess general intelligence. We used a shortened version with a 10-minute time limit, which has been shown to be correlated with mathematical performance (Cui et al., 2017; Kyttala \& Lehto, 2008; Rohde \& Thompson, 2007; Wei et al., 2012). A figure with a missing segment was presented on the screen with 6 to 8 other items. Participants were asked to use the computer mouse to choose which of the items was suitable to complete the figure according to its inherent regularity. The participants completed 5 practice trials before the formal task, which contained 76 trials.

10. Choice reaction time. This test was used to assess response speed and has been used in previous studies (Cui et al., 2017; Zhou et al., 2015). A white dot was presented on a black screen to the left or right of a white fixation cross. Participants pressed the "Q" key as fast as they could with the forefingers of their left hands if the white dot appeared on the left of the cross, and pressed the "P" key with the forefingers of their right hands if it appeared on the right. There were 30 trials (15 trials with the dot on the left and 15 with the dot on the right). Inter-stimulus intervals 
varied randomly between 1500 and 3000 ms. The median reaction time and accuracy (percentage of correct trials) were recorded, but the gross mean percent of correct responses for the test was $98 \%(\mathrm{SD}=5.3)$, and hence was not further analyzed.

11. Sentence completion. This test assessed language processing ability. It was similar to the one used by Siegel and Ryan (1988) and So and Siegel (1997) and has been used in previous studies (Wei et al., 2012; Zhou \& Cheng, 2015). Materials in the test were adapted from the language tests used in recent Chinese college entrance exams. In each trial, a sentence with one missing word was presented in the center of the screen. Participants were asked to complete the sentence by choosing one of two words presented beneath the sentence. Choices were made by pressing the "Q" or "P" keys for left or right options, respectively. The stimuli remained on the screen until the participants responded. There were 120 trials and the test was limited to 5 minutes. The adjusted number of correct trials was used as the index.

\section{Procedure}

Data was collected from December 2016 to November 2017. Participant responses were automatically recorded and transmitted over the Internet to a server located in our laboratory at Beijing Normal University.

The children were tested individually and asked to complete all the tests on computers in quiet rooms. Before each test, the experimenter explained the instructions presented on the computer screen, and then participants performed a practice session before the formal test to ensure that they understood the procedure. During the practice session, the children could ask the experimenters any questions 
related to the testing. All participants completed the 10 tests for non-symbolic number sense, arithmetic computation, general cognition, and language processing (Figure 2). All mental abacus experts also completed the mental abacus level test to identify their levels. The entire experiment lasted 70 minutes. All participants completed the tests in the same order, and had a 30-minute rest during the experiment.

\section{Data analyses}

All participant scores were used and no data were excluded from the analysis.

Descriptive statistics for 10 tests (except mental abacus level test) were calculated, including means and standard deviations of all measures for each test. Group differences were calculated and scatter plots were made to visually show the differences in non-symbolic number sense. Pearson's correlation analyses were used to investigate relationships among the 11 tests. A series of linear hierarchical regression analyses were performed to test the role of non-symbolic number sense and visual form perception in arithmetic computation, after controlling for gender and all other types of general cognitive processes. Lastly, as implemented in PROSESS by Hayes (2012), we used a meditation model to investigate the contribution of nonsymbolic number sense in mediating the relationship between arithmetic and mental abacus ability. This procedure is a variation on the Sobel (1982) test that accounts for the non-normal distribution of the $\alpha \beta$ path through bootstrapping procedures (number of resamplings $=1000$ ). 


\section{Results}

The means and standard deviations for the 10 tests (including mathematics, general cognitive processing, and language processing) were displayed in Table 1. The split-half reliabilities of tests, except verbal working memory, were also displayed in Table 1, and ranged from .84 to .98 .

\section{Intercorrelation among all measures}

The raw Pearson's correlation coefficients between scores of all 11 tests were displayed in Table 2 (below diagonal), with Bonferroni correction. The corrected $p$ values in Table 2 (set to .05) corresponded to an original $p$-value of $.00055(.05 / 91$ correlations). The results show close association between mental abacus scores and non-symbolic number sense $(r=.39)$, and also between mental abacus scores and arithmetic $(r=.58)$. The differences in the relations between non-symbolic number sense, accuracy of figure matching and other cognitive abilities were analyzed via $Z_{H}$ score, which is an updated version of Steiger's Z that uses a web-based calculator for testing the statistical significance of the difference between dependent correlations (proposed by Steiger, 1980, see http://www.psychmike.com/dependent_correlations.php). The highest correlation was found between non-symbolic number sense and accuracy in figure matching $(r=.61)$, which was significantly higher than all other correlations $(r=-.17 \sim .44)$, with $\mathrm{Z}_{\mathrm{H}}=$ $2.58 \sim 4.89$ and $p<.010$.

The partial correlation results after controlling for age and gender are shown in Table 2 (above diagonal), with the same Bonferroni correction. The results show 
similarly close association between mental abacus scores and non-symbolic number sense $(r=.36)$, and also between mental abacus scores and arithmetic $(r=.56)$.

The differences in the relations between non-symbolic number sense, and accuracy in figure matching and other cognitive abilities were similarly analyzed. There is the highest partial correlation remained between non-symbolic number sense and accuracy in figure matching $(r=.58)$, which was significantly higher than all other correlations $(r=-.09 \sim .40)$, with $\mathrm{Z}_{\mathrm{H}}=2.45 \sim 6.08$ and $p<.015$.

\section{Group differences}

The group differences calculated by multivariate analyses (without any controlled factors) showed that children in the mental abacus group performed significantly better on almost every test, except processing speed (Table 1).

However, after controlling for influence of general IQ (score of nonverbal matrix reasoning), significant group differences were only found in arithmetic fluency (score of subtraction, $\left.F_{(1,148)}=54.50, p<.001, M S E=5436.06, \eta_{\mathrm{p}}{ }^{2}=33.35 \%\right)$, non-symbolic number sense (accuracy of numerosity comparison, $F_{(1,148)}=17.65, p<.001, M S E=$ $3494.51, \eta_{\mathrm{p}}{ }^{2}=17.65 \%$ ), and verbal working memory (forward, $F_{(1,148)}=24.95, p$ $<.001, M S E=112.67, \eta^{2}=21.52 \% ;$ backward, $F_{(1,148)}=26.31, p<.001, M S E=$ $\left.110.94, \eta_{\mathrm{p}}^{2}=21.73 \%\right)$

The group differences in non-symbolic approximate number sense and arithmetic fluency could not be fully explained by any type of other cognitive processing, age, or gender (all $F$ values for the main effect of group $>11.0$ and associated $p$ values 
$<.001)$.

The group effects for non-symbolic number sense and arithmetic fluency were relatively independent and could not explain each other. Specifically, significant group differences in non-symbolic number sense remained after controlling for all the cognitive factors, as well as age and gender, and even arithmetic fluency $\left(F_{(1,136)}=\right.$ $\left.14.328, p<.001, M S E=4632.463, \eta_{\mathrm{p}}{ }^{2}=0.234\right)$. Similarly, the group differences for arithmetic fluency remained significant after controlling for all cognitive factors as well as age and gender, and even non-symbolic number sense $\left(F_{(1,135)}=36.372, p\right.$ $\left.<.001, M S E=6305.52, \eta_{\mathrm{p}}{ }^{2}=0.367\right)$.

The non-symbolic number sense has also been indexed by Weber's fraction (e.g., Pica et al., 2004; Halberda et al., 2008). The analysis on the Weber's fraction for the numerosity comparison task was introduced here, following the method used in Halberda et al(2008).

Research revealed that when the numbers of dots $n 1$ and $n 2$ satisfy the Gauss distribution, participants' Weber's fractions are dependent on the error rates in the test. The relationship between Weber's fractions and error rates is as follows:

$$
\mathrm{P}_{\text {comparison }}=\frac{1}{2} \operatorname{erfc}\left(\frac{A B S\left(n_{1}-n_{2}\right)}{\sqrt{2} * w * \sqrt{{n_{1}{ }^{2}+n_{2}{ }^{2}}^{2}}}\right)
$$

$\mathrm{n} 1$ is the average (or total) number of dots in the smaller (or larger) side in each trial, and $\mathrm{n} 2$ is the number of points in the other side. Erfc is a Gauss error function, which can be calculated in data processing software (Matlab R2018a in this study). In this study, the total number of dots in smaller side is 1484 (n1). The total number of dots in the other side is 2064 (n2). The Weber's fraction of each participant can be 
calculated with his/her own error rate data.

We analyzed the accuracy rate and Weber's fraction of the participants for all 6 types of ratios in test of non-symbolic number sense, as shown in Figure 3. . We also calculated average value of Weber's fractions for both groups, as shown in bar graphs in the lower right corner of each subfigure in Figure 3.

The ANOVA results show that there exists interaction effect (group $\times$ accuracy rate), with $F_{(5,148)}=3.26, p=.006, \eta_{p}{ }^{2}=2.16 \%$. The results of simple effect analysis show that the accuracy rates of mental abacus group are significant higher than that of control group in each ratio, with $p=7.64 \times 10^{-6}, 95 \% \mathrm{CI}=[.068, .169]$ for ratio 2.00 (the simplest), $p=8.00 \times 10^{-7}, 95 \% \mathrm{CI}=[.076, .170]$ for ratio $1.67, p=$ $1.82 \times 10^{-6}, 95 \% \mathrm{CI}=[.069, .159]$ for ratio $1.50, p=1.02 \times 10^{-5}, 95 \% \mathrm{CI}=[.057, .143]$ for ratio $1.33, p=4.42 \times 10^{-4}, 95 \% \mathrm{CI}=[.032, .111]$ for ratio 1.20 , and $p=.008,95 \%$ $C I=[.014, .091]$ for ratio 1.13 (the most difficult). The association between nonsymbolic number sense and arithmetic fluency

Figure 4 showed the scatter plots of $\mathrm{Z}$ scores for non-symbolic number sense in both groups without any controlled factors and with certain factors controlled. The fitted trend-line showed that significant group differences existed after controlling for all the general cognitive factors, as well as language and arithmetic processing, and it was almost the same in each age group.

The non-symbolic number sense might mediate the mental abacus training and arithmetic ability (after controlling for gender, age, general cognitive processing, and language processing). The mediation analysis was conducted (Figure 5). For the 
mediation analysis, the dependent variable was the residuals of arithmetic computation after controlling for 9 cognitive processing variables as well as age and gender. The mediation model shows that non-symbolic number sense partially mediated the relation between mental abacus ability and arithmetic ability. The mediation effect accounted for about $16.67 \%$ of the total effect.

\section{The correlation between non-symbolic number sense and mental abacus ability}

The significant partial correlation between non-symbolic number sense and mental abacus scores remained after controlling for each type of cognitive ability as well as age and gender $(r=.24-.39, p<.004)$, and even after controlling for all the factors together $(r=.32, p<.001)$.

\section{Discussion}

The current investigation aimed at exploring the group differences between children skilled in mental abacus and children naive to mental abacus in approximate number sense. As expected, children in the mental abacus group performed much better on arithmetic and approximate number sense than their control peers, and this group difference was robust after controlling for age, gender, general cognitive processing and even arithmetic performance.

Children in the mental abacus group outperformed controls in arithmetic ability, consistent with numerous previous studies (Amaiwa \& Hatano, 1989; Barner et al., 
2016; Chen et al., 2006; Donlan \& Wu, 2017; Hanakawa et al., 2003; Ku et al., 2012;

Na et al., 2015; Shen, 1999; Stigler, 1984; C. J. Wang et al., 2015; Wu et al., 2009).

The advantage in the approximate number sense for children skilled in mental abacus is consistent with the fact that the abacus and mental abacus are based on the human's non-symbolic number system. The approximate number sense is in nature the ability in the non-symbolic number system. The non-symbolic number processing in abacus and mental abacus is exact other than approximate, as a nonlinguistic format for exact numerical computation (Frank \& Barner, 2012).

The result that there was advantage for children skilled in mental abacus is not consistent with the finding in two previous studies on the effect of mental abacus training (Barner et al., 2016; Sullivan et al., 2016). Current investigation found that the mental abacus level is closely associated with the ANS. The two studies did not report the children's mental abacus level.

Literatures have reported that different levels of abacus mental arithmetic learners exhibited different levels of non-symbolic number sense (Brooks et al., 2004).

Children skilled in mental abacus did not show the advantage in visual perception as measured by figure matching task. The ANS has been shown to be closely related to visual perception (Cui et al., 2017; 2019; Zhang et al., 2016; Zhou et al., 2015). The current study shows their dissociation. After long-term training, children might have special visual strategies to process the non-symbolic number.

Studies have shown that mental abacus experts performed much better than 
controls in several types of cognitive abilities, including visual imagery (Hanakawa et al., 2003; Hatta \& Miyazaki, 1990), verbal working memory (Bhaskaran et al., 2006; Hu et al., 2011), visuospatial working memory (Bhaskaran et al., 2006; Dong et al., 2016), executive function (Wang et al., 2015; Wang, Pei, \& Cui, 2017), attention (Na et al., 2015; Yamada, 1998), and even general intelligence (Irwing, Hamza, Khaleefa, \& Lynn, 2008). The abilities can be affected by one another. Moreover, they can affect non-symbolic number sense.

According to the current results, children skilled mental abacus experts had much larger digit span, which is consistent with many previous findings (Bhaskaran et al., 2006; Dong et al., 2016; Hatano \& Osawa, 1983; Hatano et al., 1987; Hatta \& Nishiide, 1991; Hishitani, 1990; Hu et al., 2011; Kawakami et al., 1995; Li et al., 2013; Tanaka et al., 2002). Bhaskaran et al. (2006) suggested mental abacus experts have greater digit span because that they have large amount of experiences on placing numbers on the abacus image during mentally calculation with abacus methods. Tanaka et al. (2002) proposed that abacus practice would develop a more efficient manipulation method using spatial representation of large numbers, involving rulebased visuo-motor processing, rather than a sequentially organized phonological representation. Different from verbal short-term memory for digits, children skilled in mental abacus did not exhibit any significant advantage in spatial short-term memory as measured with the Corsi block task. We guess that might be attributed to their training methods, which require learners to instantaneously operate the numbers presented on an abacus as a figure, rather than add beads one by one. 
The current study controlled for general cognitive processing. The significant advantage could not be fully explained by any type of typical general cognitive ability. We note that visual perception was one of the controlling factors and has been shown to mediate the association between approximate number sense and mathematical achievement (Cui et al., 2017; Cui et al., 2019; Zhou \& Cheng, 2015; Zhou et al., 2015). The current investigation also controlled the visual perception as well as other cognitive processing. The results suggested that better approximate number sense for children skilled in mental abacus might not originate in their superior cognitive abilities.

The current investigation cannot speak to any causal relationships. We can confidently say that being an expert in mental abacus is associated with better approximate number sense, even after controlling for age, gender, language processing, various types of general cognitive ability, and arithmetic. However, we cannot exclude the possibility that only children who had better non-symbolic number sense would become mental abacus experts.

Therefore, the current results provide the motivation for a further study with a strict experimental design to examine the effect that training in mental abacus has on non-symbolic number sense. An ideal experimental design would include randomized groups with pre- and post-tests.

The current study found a strong group difference in non-symbolic number sense between child experts in mental abacus and their non-expert peers, even after controlling for age, gender, general cognitive processing, language processing, and 
arithmetic. However, future studies need to examine the causal association between mental abacus training and the development of non-symbolic number sense.

Acknowledgments

This research was supported by three grants from the Natural Science Foundation of China (no. 31671151, 31600896, and 31521063). 
References

Agrillo, C., Piffer, L., \& Adriano, A. (2013). Individual differences in non-symbolic numerical abilities predict mathematical achievements but contradict ATOM. Behavioral and Brain Functions, 9, 14. doi:10.1186/1744-9081-9-26

Amaiwa, S., \& Hatano, G. (1989). Effects of abacus learning on 3rd-graders performance in paper-and-pencil tests of calculation. Japanese Psychological Research, 31(4), 161-168. doi:10.4992/psycholres1954.31.161

Anobile, G., Cicchini, G. M., \& Burr, D. C. (2014). Separate Mechanisms for Perception of Numerosity and Density. Psychological Science, 25(1), 265-270. doi:10.1177/0956797613501520

Anobile, G., Stievano, P., \& Burr, D. C. (2013). Visual sustained attention and numerosity sensitivity correlate with math achievement in children. Journal of Experimental Child Psychology, 116(2), 380-391.

Barner, D., Alvarez, G., Sullivan, J., Brooks, N., Srinivasan, M., \& Frank, M. C. (2016). Learning Mathematics in a Visuospatial Format: A Randomized, Controlled Trial of Mental Abacus Instruction. Child Development, 87(4), 1146-1158. doi:10.1111/cdev.12515

Berg, D. H. (2008). Working memory and arithmetic calculation in children: The contributory roles of processing speed, short-term memory, and reading. Journal of Experimental Child Psychology, 99(4), 288-308. doi:10.1016/j.jecp.2007.12.002

Bhaskaran, M., Sengottaiyan, A., Madhu, S., \& Ranganathan, V. (2006). Evaluation of memory in abacus learners. Indian journal of physiology and pharmacology, 50(3), 225-233.

Brooks, N. B. , Barner, D. , Frank, M. , \& Susan Goldin cm eadow. (2017). The role of gesture in supporting mental representations: the case of mental abacus arithmetic. Cognitive Science A Multidisciplinary Journal, 42(1). doi:10.1111/cogs. 12527

Boonen, A. J. H., van Wesel, F., Jolles, J., \& van der Schoot, M. (2014). The role of visual representation type, spatial ability, and reading comprehension in word problem solving: An item-level analysis in elementary school children. International Journal of Educational Research, 68, 15-26. doi:10.1016/j.ijer.2014.08.001

Bull, R., \& Johnston, R. S. (1997). Children's arithmetical difficulties: Contributions from processing speed, item identification, and short-term memory. Journal of Experimental Child Psychology, 65(1), 1-24. doi:10.1006/jecp.1996.2358

Chalip, L., \& Stigler, J. W. (1986). The Development of Achievement and Ability among Chinese Children: A New Contribution to an Old Controversy. Journal of Educational Research, 79(5), 302-307.

Chen, C. L., Wu, T. H., Cheng, M. C., Huang, Y. H., Sheu, C. Y., Hsieh, J. C., \& Lee, J. S. (2006). Prospective demonstration of brain plasticity after intensive abacus-based mental calculation training: An fMRI study. Nuclear Instruments \& Methods In Physics Research Section a-Accelerators Spectrometers 
Detectors And Associated Equipment, 569(2), 567-571. doi:10.1016/j.nima.2006.08.101

Cirino, M. (2011). Hemingway's "Big Two-Hearted River": Nick's Strategy and the Psychology of Mental Control. Papers on Language and Literature, 47(2), 115-140.

Corsi, P. M. (1972). Human memory and the medial temporal region of the brain. Doctoral Dissertation, Mcgill University.

Cowan, R., \& Powell, D. (2014). The Contributions of Domain-General and Numerical Factors to Third-Grade Arithmetic Skills and Mathematical Learning Disability. Journal of Educational Psychology, 106(1), 214-229. doi:10.1037/a0034097

Cui, J., Zhang, Y., Cheng, D., Li, D., \& Zhou, X. (2017). Visual form perception can be a cognitive correlate of lower level math categories for teenagers. Frontiers in Psychology, 8, 1336.

DeWind, N. K., \& Brannon, E. M. (2012). Malleability of the approximate number system: effects of feedback and training. Frontiers In Human Neuroscience, 6, 10. doi:10.3389/fnhum.2012.00068

Dong, S. S., Wang, C. J., Xie, Y., Hu, Y. Z., Weng, J., \& Chen, F. Y. (2016). The impact of abacus training on working memory and underlying neural correlates in young adults. Neuroscience, 332, 181-190. doi:10.1016/j.neuroscience.2016.06.051

Donlan, C., \& Wu, C. (2017). Procedural complexity underlies the efficiency advantage in abacus-based arithmetic development. Cognitive Development, 43, 14-24. doi:10.1016/j.cogdev.2017.02.002

Du, F. L., Chen, F. Y., Li, Y. X., Hu, Y. Z., Tian, M., \& Zhang, H. (2013). Abacus training modulates the neural correlates of exact and approximate calculations in chinese children: An fmri study. Biomed Research International, 12. doi:10.1155/2013/694075

Ekstrom, R. B. R., French, J. J. W., Harman, H. H., \& Dermen, D. (1976). Manual for kit of factor-referenced cognitive tests. Princeton Nj Educational Testing Service.

Frank, M. C., \& Barner, D. (2012). Representing Exact Number Visually Using Mental Abacus. Journal of Experimental Psychology-General, 141(1), 134149. doi:10.1037/a0024427

Fuchs, L. S., Fuchs, D., Compton, D. L., Hamlett, C. L., \& Wang, A. Y. (2015). Is Word-Problem Solving a Form of Text Comprehension? Scientific Studies of Reading, 19(3), 204-223. doi:10.1080/10888438.2015.1005745

Fuchs, L. S., Fuchs, D., Hamlet, C. L., Powell, S. R., Capizzi, A. M., \& Seethaler, P. M. (2006). The effects of computer-assisted instruction on number combination skill in at-risk first graders. Journal of Learning Disabilities, 39(5), 467-475. doi:10.1177/00222194060390050701

Fuhs, M. W., McNeil, N. M., Kelley, K., O'Rear, C., \& Villano, M. (2016). The role of non-numerical stimulus features in approximate number system training in preschoolers from low-income homes. Journal of Cognition and Development, 
17(5), 737-764. doi:10.1080/15248372.2015.1105228

Gebuis, T., Kadosh, R. C., \& Gevers, W. (2016). Sensory-integration system rather than approximate number system underlies numerosity processing: A critical review. Acta Psychologica, 171, 17-35. doi:10.1016/j.actpsy.2016.09.003

Green, C. S., \& Bavelier, D. (2003). Action video game modifies visual selective attention. Nature, 423(6939), 534-537. doi:10.1038/nature01647

Guilford, J. P., \& Guilford, R. B. (1936). Personality Factors S, E, and M, and their Measurement. Journal of Psychology Interdisciplinary \& Applied, 2(1), 109127.

Halberda, J., Mazzocco, M. M. M., \& Feigenson, L. (2008). Individual differences in non-verbal number acuity correlate with maths achievement. Nature, 455(7213), 665-8. doi:10.1038/nature07246

Hanakawa, T., Honda, M., Okada, T., Fukuyama, H., \& Shibasaki, H. (2003). Neural correlates underlying mental calculation in abacus experts: A functional magnetic resonance imaging study. Neuroimage, 19(2), 296-307. doi:10.1016/s1053-8119(03)00050-8

Hatano, G., Miyake, Y., \& Binks, M. G. (1977). Performance of expert abacus operators. Cognition, 5(1), 47-55.

Hatano, G., \& Osawa, K. (1983). Digit memory of grand experts in abacus-derived mental calculation. Cognition, 15(1-3), 95-110. doi:10.1016/00100277(83)90035-5

Hatano, G., Shimizu, K., \& Amaiwa, S. (1987). Formation of a mental abacus for computation and its use as a memory device for digits - a developmentalstudy. Developmental Psychology, 23(6), 832-838. doi:10.1037//00121649.23.6.832

Hatta, T., \& Miyazaki, M. (1990). Visual imagery processing in Japanese abacus experts. Imagination Cognition \& Personality, 9(2), 91-102.

Hatta, T., \& Nishiide, S. (1991). Teachers' stress in Japanese primary schools: Comparison with workers in private companies. Stress \& Health, 7(4), 207211.

Hecht, S. A., Torgesen, J. K., Wagner, R. K., \& Rashotte, C. A. (2001). The relations between phonological processing abilities and emerging individual differences in mathematical computation skills: A longitudinal study from second to fifth grades. Journal of Experimental Child Psychology, 79(2), 192-227. doi:10.1006/jecp.2000.2586

Hedden, T., \& Yoon, C. (2006). Individual differences in executive processing predict susceptibility to interference in verbal working memory. Neuropsychology, 20(5), 511-528. doi:10.1037/0894-4105.20.5.511.supp

Hishitani, S. (1990). Imagery experts - how do expert abacus operators process imagery. Applied Cognitive Psychology, 4(1), 33-46. doi:10.1002/acp.2350040104

Hu, Y., Geng, F., Tao, L., Hu, N., Du, F., Fu, K., \& Chen, F. (2011). Enhanced white matter tracts integrity in children with abacus training. Human Brain Mapping, $32(1), 10-21$. 
Huang, J., Du, F. L., Yao, Y., Wan, Q., Wang, X. S., \& Chen, F. Y. (2015). Numerical magnitude processing in abacus-trained children with superior mathematical ability: An EEG study. Journal of Zhejiang University-Science B, 16(8), 661671. doi:10.1631/jzus.B1400287

Hyde, D. C., Khanum, S., \& Spelke, E. S. (2014). Brief non-symbolic, approximate number practice enhances subsequent exact symbolic arithmetic in children. Cognition, 131(1), 92-107. doi:10.1016/j.cognition.2013.12.007

Irwing, P., Hamza, A., Khaleefa, O., \& Lynn, R. (2008). Effects of Abacus training on the intelligence of Sudanese children. Personality and Individual Differences, 45(7), 694-696. doi:10.1016/j.paid.2008.06.011

Jordan, N. C., Hansen, N., Fuchs, L. S., Siegler, R. S., Gersten, R., \& Micklos, D. (2013). Developmental predictors of fraction concepts and procedures. Journal of Experimental Child Psychology, 116(1), 45-58. doi:10.1016/j.jecp.2013.02.001

Kawakami, Y., Abe, T., Kuno, S. Y., \& Fukunaga, T. (1995). Training-induced changes in muscle architecture and specific tension. European Journal of Applied Physiology \& Occupational Physiology, 72(1-2), 37-43.

Ku, Y. X., Hong, B., Zhou, W. J., Bodner, M., \& Zhou, Y. D. (2012). Sequential neural processes in abacus mental addition: an eeg and fmri case study. Plos One, 7(5), 15. doi:10.1371/journal.pone.0036410

Kyttala, M., \& Lehto, J. E. (2008). Some factors underlying mathematical performance: The role of visuospatial working memory and non-verbal intelligence. European Journal of Psychology Of Education, 23(1), 77-94. doi:10.1007/bf03173141

Kyttala, P., Erkkola, M., Lehtinen-Jacks, S., Ovaskainen, M. L., Uusitalo, L., Veijola, R., . . . Virtanen, S. M. (2014). Finnish Children Healthy Eating Index (FCHEI) and its associations with family and child characteristics in preschool children. Public Health Nutrition, 17(11), 2519-2527. doi:10.1017/s1368980013002772

Leibovich, T., Katzin, N., Harel, M., \& Henik, A. (2017). From "sense of number" to "sense of magnitude": The role of continuous magnitudes in numerical cognition. Behavioral and Brain Sciences, 40, 1-16. doi:10.1017/s0140525x16000960

Li, Y., Chen, F., \& Huang, W. (2016). Neural plasticity following abacus training in humans: a review and future directions. Neural Plasticity,2016,(2016-1-4), 2016(3), 1213723. doi:10.1155/2016/1213723

Li, Y. X., Wang, Y. Q., Hu, Y. Z., Liang, Y. R., \& Chen, F. Y. (2013). Structural changes in left fusiform areas and associated fiber connections in children with abacus training: evidence from morphometry and tractography. Frontiers In Human Neuroscience, 7, 8. doi:10.3389/fnhum.2013.00335

Lindskog, M., Winman, A., \& Poom, L. (2016). Arithmetic training does not improve approximate number system acuity. Frontiers in Psychology, 7(e33832).

Looi, C. Y., Lim, J., Sella, F., Lolliot, S., Duta, M., Avramenko, A. A., \& Kadosh, R. C. (2017). Transcranial random noise stimulation and cognitive training to 
improve learning and cognition of the atypically developing brain: A pilot study. Scientific Reports, 7, 10. doi:10.1038/s41598-017-04649-x

Meng X. (2016). Striding forward in the interweaving of history and reality -Commemorating the 3rd Anniversary of the success of the application for World Cultural Heritage of "Chinese abacus". Abacus and mental abacus, 6, 5-7.

Menninger, K.W. (1969). Number words and number symbols: A cultural historv of numbers. Cambridge, MA: MIT Press.

Miller, K. F., \& Stigler, J. W. (1991). Meanings of skill: Effects of abacus expertise on number representation. Cognition \& Instruction, 8(1), 29-67.

Na, K. S., Lee, S. I., Park, J. H., Jung, H. Y., \& Ryu, J. H. (2015). Association between abacus training and improvement in response inhibition: a casecontrol study. Clinical Psychopharmacology and Neuroscience, 13(2), 163167. doi:10.9758/cpn.2015.13.2.163

Ni X. (2007). The revision basis and empirical analysis of the standard of abacus mental calculation in China. Abacus and mental abacus, 2, 38-41.

Obersteiner, A., Reiss, K., \& Ufer, S. (2013). How training on exact or approximate mental representations of number can enhance first-grade students' basic number processing and arithmetic skills. Learning and Instruction, 23, 125135. doi:10.1016/j.learninstruc.2012.08.004

Park, J., Bermudez, V., Roberts, R. C., \& Brannon, E. M. (2016). Non-symbolic approximate arithmetic training improves math performance in preschoolers. Journal of Experimental Child Psychology, 152, 278-293. doi:10.1016/j.jecp.2016.07.011

Park, J., \& Brannon, E. M. (2013). Training the Approximate Number System Improves Math Proficiency. Psychological Science, 24(10), 2013-2019. doi:10.1177/0956797613482944

Park, J., \& Brannon, E. M. (2014). Improving arithmetic performance with number sense training: An investigation of underlying mechanism. Cognition, 133(1), 188-200. doi:10.1016/j.cognition.2014.06.011

Pica, P., Lemer, C., Izard, V., \& Dehaene, S. (2004). Exact and approximate arithmetic in an Amazonian indigene group. Science, 306, 499-503. doi:10.1126/science.1102085

Price, G. R., Palmer, D., Battista, C., \& Ansari, D. (2012). Nonsymbolic numerical magnitude comparison: Reliability and validity of different task variants and outcome measures, and their relationship to arithmetic achievement in adults. Acta Psychologica, 140(1), 50-57. doi:10.1016/j.actpsy.2012.02.008

Purpura, D. J., \& Ganley, C. M. (2014). Working memory and language: Skill-specific or domain-general relations to mathematics? Journal of Experimental Child Psychology, 122, 104-121. doi:10.1016/j.jecp.2013.12.009

Putz, D. A., Gaulin, S. J. C., Sporter, R. J., \& McBurney, D. H. (2004). Sex hormones and finger length - What does 2D : 4D indicate? Evolution And Human Behavior, 25(3), 182-199. doi:10.1016/j.evolhumbehav.2004.03.005 Rasanen, P., Salminen, J., Wilson, A. J., Aunio, P., \& Dehaene, S. (2009). Computer- 
assisted intervention for children with low numeracy skills. Cognitive Development, 24(4), 450-472. doi:10.1016/j.cogdev.2009.09.003

Rohde, T. E., \& Thompson, L. A. (2007). Predicting academic achievement with cognitive ability. Intelligence, 35(1), 83-92. doi:10.1016/j.intell.2006.05.004

Salthouse, T. A., \& Coon, V. E. (1994). Interpretation of differential deficits - the case of aging and mental arithmetic. Journal Of Experimental PsychologyLearning Memory And Cognition, 20(5), 1172-1182. doi:10.1037/02787393.20.5.1172

Salthouse, T. A., \& Meinz, E. J. (1995). Aging, inhibition, working-memory, and speed. Journals of Gerontology Series B-Psychological Sciences and Social Sciences, 50(6), P297-P306. doi:10.1093/geronb/50B.6.P297

Sasanguie, D., \& Reynvoet, B. (2014). The relation between symbolic number processing and math achievement: opening the black box. Nov-2014.

Shen, H. (1999). Teaching mental abacus calculation to students with mental retardation. Journal of the International Association of Special Education, 7, 56-66.

Shepard, R. N., \& Metzler, J. (1971). Mental rotation of 3-dimensional objects. Science, 171(3972), 701-\&. doi:10.1126/science.171.3972.701

Stigler, J. W. (1984). "Mental abacus": The effect of abacus training on Chinese children's mental calculation. Cognitive Psychology, 16(2), 145-176. doi: 10.1016/0010-0285(84)90006-9

Swanson, H. L., Jerman, O., \& Zheng, X. H. (2009). Math disabilities and reading disabilities can they be separated? Journal of Psychoeducational Assessment, 27(3), 175-196. doi:10.1177/0734282908330578

Tanaka, S., Michimata, C., Kaminaga, T., Honda, M., \& Sadato, N. (2002). Superior digit memory of abacus experts: An event-related functional MRI study. Neuroreport, 13(17), 2187-2191. doi:10.1097/00001756-200212030-00005

Tinelli, F., Anobile, G., Gori, M., Aagten-Murphy, D., Bartoli, M., Burr, D. C., . . Morrone, M. C. (2015). Time, number and attention in very low birth weight children. Neuropsychologia, 73, 60-69.

Wang, C. J., Geng, F. J., Yao, Y., Weng, J., Hu, Y. Z., \& Chen, F. Y. (2015). Abacus training affects math and task switching abilities and modulates their relationships in chinese children. Plos One, 10(10), 15. doi:10.1371/journal.pone.0139930

Wang, J. J., Odic, D., Halberda, J., \& Feigenson, L. (2016). Changing the precision of presthoolers' approximate number system representations changes their symbolic math performance. Journal of Experimental Child Psychology, 147, 82-99. doi:10.1016/j.jecp.2016.03.002

Wang, Y., Pei, D., \& Cui, X. (2017). Pseudo-spherical normal Darboux images of curves on a lightlike surface. Mathematical Methods in the Applied Sciences, 40(18), 7151-7161. doi:10.1002/mma.4519

Wechsler D. (1997). Wechsler Adult Intelligence Scale - third edition. San Antonio, TX: The Psychological Corporation.

Wei, W., Chen, C. S., Dong, Q., \& Zhou, X. L. (2016). Sex differences in gray matter 
volume of the right anterior hippocampus explain sex differences in threedimensional mental rotation. Frontiers In Human Neuroscience, 10, 9. doi:10.3389/fnhum.2016.00580

Wei, W., Yuan, H. B., Chen, C. S., \& Zhou, X. L. (2012). Cognitive correlates of performance in advanced mathematics. British Journal Of Educational Psychology, 82(1), 157-181. doi:10.1111/j.2044-8279.2011.02049.x

Wilson, A. J., Revkin, S. K., Cohen, D., Cohen, L., \& Dehaene, S. (2006). An open trial assessment of "The Number Race", An adaptive computer game for remediation of dyscalculia. Behavioral and brain functions : BBF, 2, 20. doi:10.1186/1744-9081-2-20

Wu, T. H., Chen, C. L., Huang, Y. H., Liu, R. S., Hsieh, J. C., \& Lee, J. J. S. (2009). Effects of long-term practice and task complexity on brain activities when performing abacus-based mental calculations: A PET study. European Journal of Nuclear Medicine \& Molecular Imaging, 36(3), 436-445.

Yamada, F. (1998). Frontal midline theta rhythm and eyeblinking activity during a VDT task and a video game: Useful tools for psychophysiology in ergonomics. Ergonomics, 41(5), 678-688. doi:10.1080/001401398186847

Zhou, X., Cheng, D. (2015). When and why numerosity processing is associated with developmental dyscalculia. In S. Chinn (Ed.), The Routledge international handbook of dyscalculia and mathematical learning difficulties (pp. 78-89). New York: Routledge.

Zhou, X., Wei, W., Zhang, Y., Cui, J., \& Chen, C. (2015). Visual perception can account for the close relation between numerosity processing and computational fluency. Frontiers in Psychology, 6(1364), 1364. doi:10.3389/fpsyg.2015.01364 
Table 1: Descriptive statistics for the 10 measures in the current study and $F$ test results for group differences.

\begin{tabular}{|c|c|c|c|c|c|c|c|}
\hline Test & Index & $\begin{array}{c}\text { Mental abacus } \\
\text { Mean }(S D)\end{array}$ & $\begin{array}{c}\text { Control Mean } \\
(S D)\end{array}$ & $F$ value & $p$ value & $\begin{array}{r}\text { Cohen's } \\
d\end{array}$ & $\begin{array}{l}\text { Split-half } \\
\text { reliability }\end{array}$ \\
\hline Subtraction & Adjusted No. of correct response & $47.0(6.5)$ & $34.9(10.3)$ & 74.066 & $<.001$ & 1.45 & .91 \\
\hline Numerosity comparison (ACC) & Accuracy & 77.7(9.4) & $68.1(11.5)$ & 31.723 & $<.001$ & 0.92 & .92 \\
\hline Numerosity comparison (RT) & Reaction time (millisecond) & $728(144)$ & $693(206)$ & 1.427 & .234 & 0.20 & .96 \\
\hline Figure matching (ACC) & Accuracy & $68.3(10.3)$ & $63.2(9.8)$ & 9.780 & .002 & 0.51 & .87 \\
\hline Figure matching (RT) & Reaction time (millisecond) & $1221(308)$ & $1184(329)$ & 0.489 & .485 & 0.12 & .98 \\
\hline Visual searching & Adjusted No. of correct response & $44.4(23.3)$ & $36.6(20.2)$ & 4.823 & .030 & 0.33 & .93 \\
\hline Three-dimensional mental rotation & Adjusted No. of correct response & 16.8(9.6) & 13.5(9.6) & 4.288 & .040 & 0.34 & .86 \\
\hline Spatial working memory & Accuracy & $78.2(5.6)$ & $75.2(5.8)$ & 10.185 & .002 & 0.52 & .84 \\
\hline Verbal working memory (forward) & Maximum number & $9.0(1.7)$ & 7.3(1.6) & 40.588 & $<.001$ & 1.04 & - \\
\hline Verbal working memory (backward) & Maximum number & $6.7(1.6)$ & $4.9(1.7)$ & 41.083 & $<.001$ & 1.04 & - \\
\hline Nonverbal matrix reasoning & Adjusted No. of correct response & $22.3(5.3)$ & $18.9(5.3)$ & 15.751 & $<.001$ & 0.65 & .90 \\
\hline Choice reaction time & Reaction time (millisecond) & $513(108)$ & $551(273)$ & 1.224 & .270 & -0.19 & .97 \\
\hline Sentence completion & Adjusted No. of correct response & $25.0(10.0)$ & $20.2(10.0)$ & 8.581 & .004 & 0.48 & .91 \\
\hline
\end{tabular}

Note: Adjusted no. of correct trials = Total correct trials minus total incorrect trials. This adjustment was made to control for the effect of guessing in multiple choice tests. 
Table 2: Pearson's correlations between the measures used in the study (below diagonal) and partial correlations (controlling for age and gender; above diagonal).

\begin{tabular}{|c|c|c|c|c|c|c|c|c|c|c|c|c|c|c|}
\hline & 1 & 2.1 & 2.2 & 3.1 & 3.2 & 4 & 5 & 6 & 7.1 & 7.2 & 8 & 9 & 10 & 11 \\
\hline 1.Subtraction & - & $.38^{*}$ & .04 & $.37^{*}$ & .14 & $.29^{*}$ & .13 & $.30^{*}$ & $.36^{*}$ & $.37^{*}$ & $.32^{*}$ & -.24 & $.43^{*}$ & $.56^{*}$ \\
\hline 2.1 Numerosity comparison (ACC) & $.43^{*}$ & - & $.50^{*}$ & $.58^{*}$ & $.40^{*}$ & .26 & .27 & $.38^{*}$ & $.32^{*}$ & .20 & $.43^{*}$ & -.09 & $.37^{*}$ & $.36^{*}$ \\
\hline 2.2 Numerosity comparison (RT) & -.06 & $.40^{*}$ & - & .24 & $.51^{*}$ & .08 & .11 & .14 & .13 & .16 & .16 & $.34^{*}$ & .09 & .17 \\
\hline 3.1 Figure matching (ACC) & $.45^{*}$ & $.61^{*}$ & .11 & - & $.42^{*}$ & $.32^{*}$ & .27 & $.45^{*}$ & .27 & .24 & $.42^{*}$ & -.09 & $.36^{*}$ & .17 \\
\hline 3.2 Figure matching (RT) & .09 & $.35^{*}$ & $.52^{*}$ & $.33^{*}$ & - & $.35^{*}$ & $.31^{*}$ & .24 & .26 & .16 & $.36^{*}$ & -.05 & .21 & .03 \\
\hline 4. Visual searching & $.32^{*}$ & $.29^{*}$ & .03 & $.35^{*}$ & $.32^{*}$ & - & $.35^{*}$ & $.31^{*}$ & .26 & .26 & $.36^{*}$ & -.15 & .21 & .16 \\
\hline 5. Three-dimensional mental rotation & .21 & $.29^{*}$ & .04 & $.34^{*}$ & .26 & $.36^{*}$ & - & .22 & .22 & $.29^{*}$ & $.41^{*}$ & -.10 & .18 & .10 \\
\hline 6. Spatial working memory & $.38^{*}$ & $.44^{*}$ & .02 & $.51^{*}$ & .17 & $.34^{*}$ & .26 & - & .24 & $.28^{*}$ & $.45^{*}$ & -.18 & $.30^{*}$ & .24 \\
\hline 7.1 Verbal working memory (forward) & $.45^{*}$ & $.38^{*}$ & -.00 & $.39^{*}$ & .18 & $.30^{*}$ & $.31^{*}$ & $.35^{*}$ & - & $.48^{*}$ & $.35^{*}$ & -.07 & $.42^{*}$ & $.55^{*}$ \\
\hline 7.2 Verbal working memory (backward) & $.45^{*}$ & .27 & .04 & $.35^{*}$ & .10 & $.29^{*}$ & $.36^{*}$ & $.37^{*}$ & $.56^{*}$ & - & $.32^{*}$ & -.07 & $.33^{*}$ & $.52^{*}$ \\
\hline 8. Nonverbal matrix reasoning & $.40^{*}$ & $.47^{*}$ & .04 & $.51^{*}$ & $.28^{*}$ & $.38^{*}$ & $.47^{*}$ & $.51^{*}$ & $.46^{*}$ & $.42^{*}$ & - & -.24 & $.42^{*}$ & $.30^{*}$ \\
\hline 9. Simple reaction time & $-.32^{*}$ & -.17 & $.40^{*}$ & -.20 & .00 & -.20 & -.15 & $-.29^{*}$ & -.20 & -.18 & $-.32^{*}$ & - & -.17 & -.01 \\
\hline 10. Sentence completion & $.52^{*}$ & $.44^{*}$ & -.10 & $.50^{*}$ & .08 & .26 & $.28^{*}$ & $.44^{*}$ & $.56^{*}$ & $.47^{*}$ & $.54^{*}$ & $-.33^{*}$ & - & $.30^{*}$ \\
\hline 11. Mental abacus score & $.58^{*}$ & $.39^{*}$ & .11 & .22 & .00 & .17 & .14 & $.28^{*}$ & $.56^{*}$ & $.54^{*}$ & $.34^{*}$ & -.06 & $.33^{*}$ & - \\
\hline
\end{tabular}

Note: ${ }^{*}$ corrected $p<.05$, original $p$-value $<.00055$ (.05/91 correlations). 
Figure 1: Schematic representation of abacus, and representation of digits from 1 to 9 by abacus.

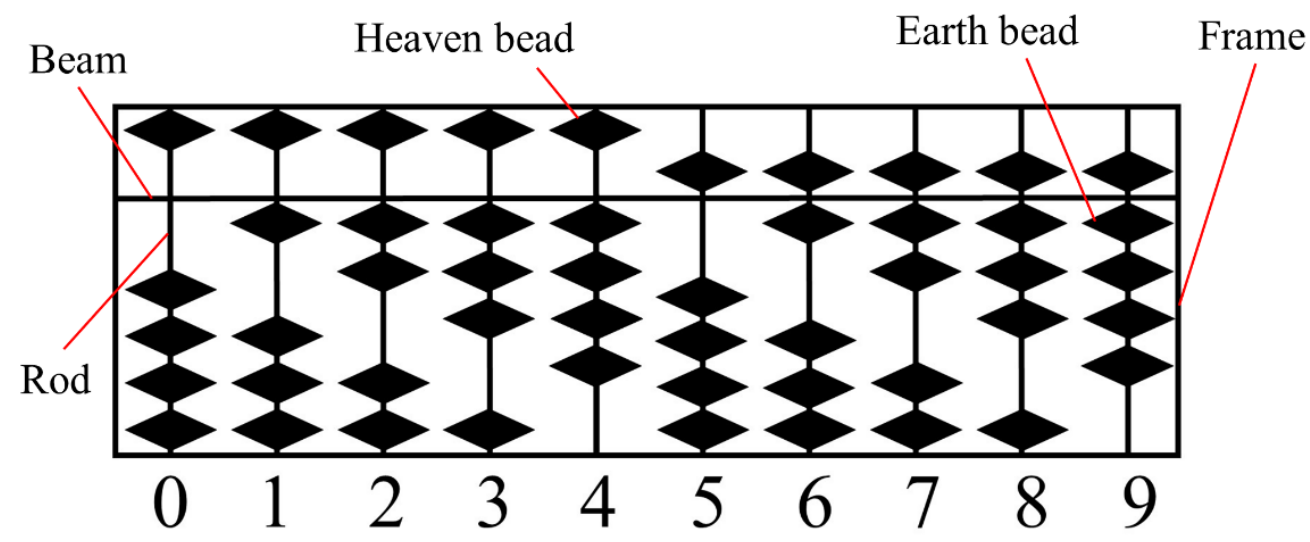


Figure 2: Schematic representation of tests used in the current study.

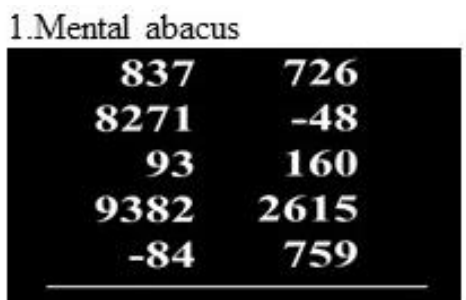

3.Numerosity comparison

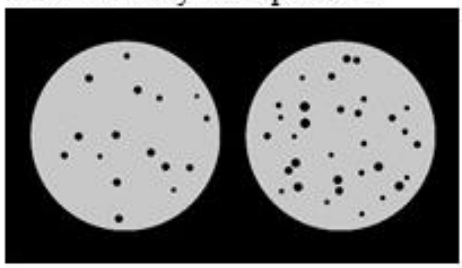

6.Three-dimensional mental rotation

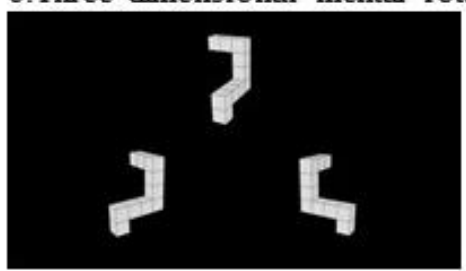

9.Nonverbal matrix reasoning

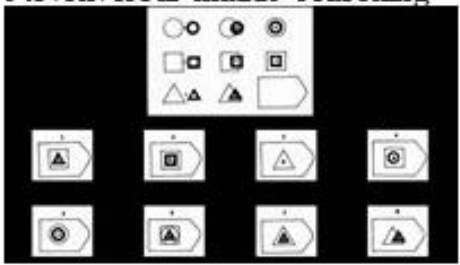

2.Subtraction

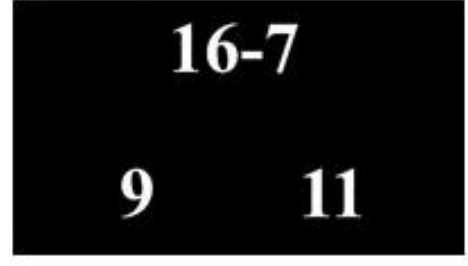

4.Figure matching

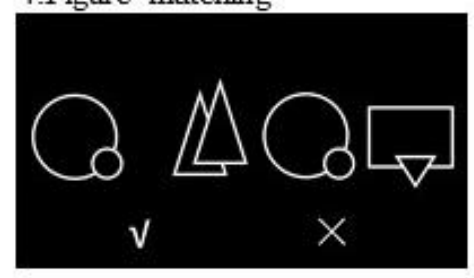

7.Spatial working memory

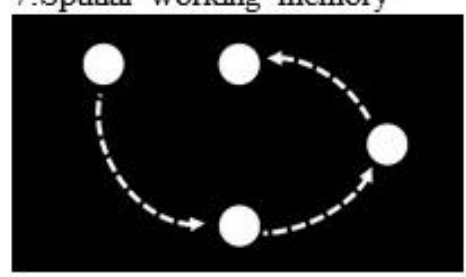

10. Choice reaction time

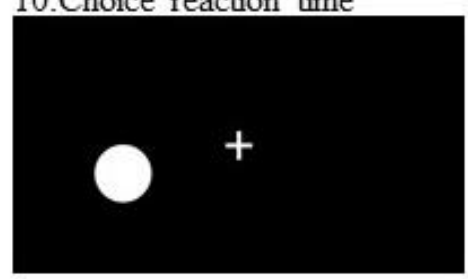

5.Visual searching

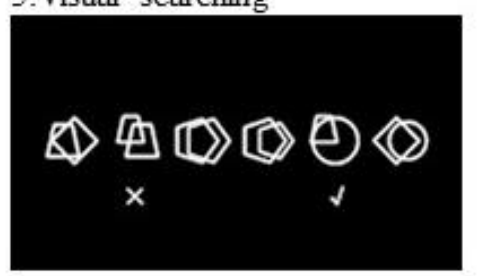

8.Verbal working memory

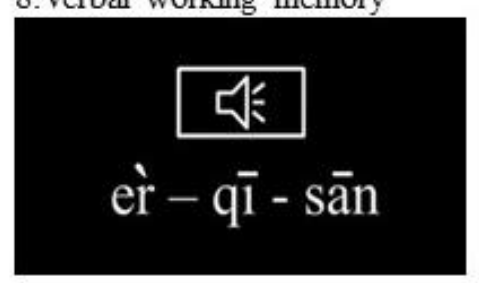

11. Sentence completion

弯弯的（）像小船

太阳

\section{月亮}


Figure 3: Scatter plots of accuracy rate for numerosity comparison task in the mental abacus group and control group. The difficulty increases from Ratio 1 to Ratio 6. Red: data of the mental abacus group; blue: data of the control group. W: Weber's fraction.
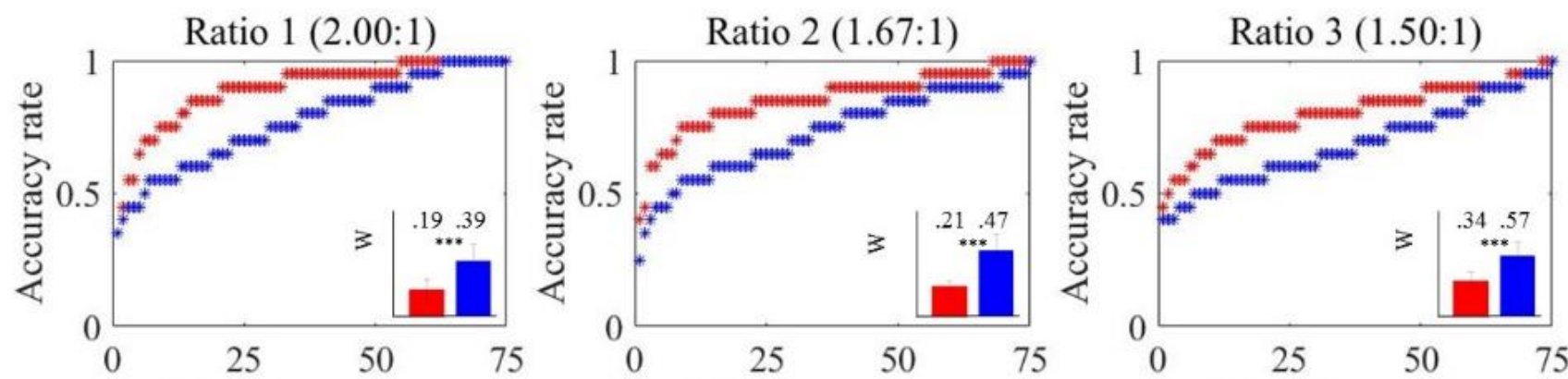

Participants

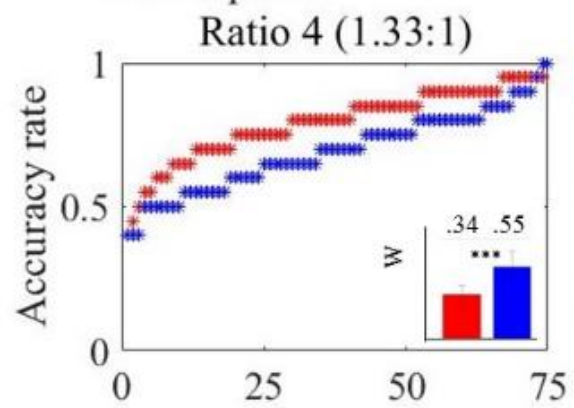

Participants

Participants

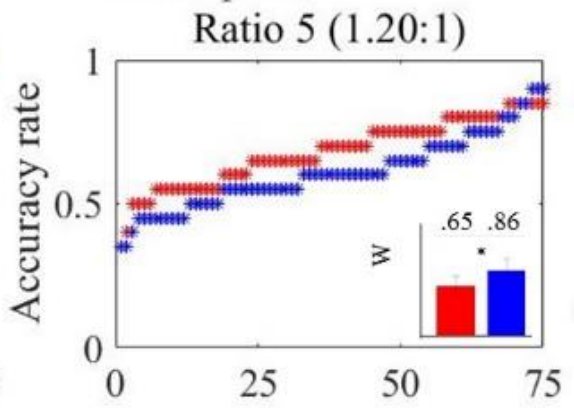

Participants

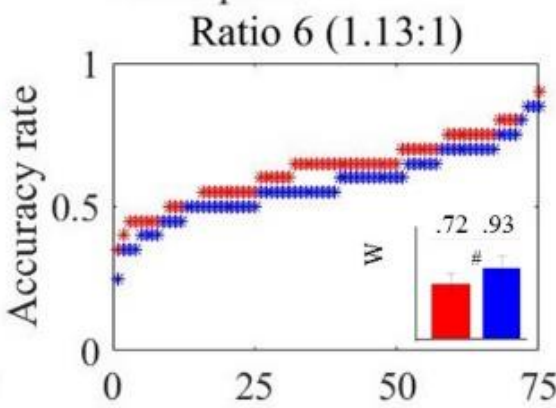

Participants

Note: The analysis about accuracy rate is represented by scatter plots and analysis about weber fraction is represented by bar chart. We used data of all the participants in the analysis about accuracy rate, but in Weber's fraction analysis, we only retain the data of the participants whose accuracy rate is more than 0.5. 
Figure 4: Scatter plot of $\mathrm{Z}$ scores for approximate number sense in the mental abacus group and control group. A: raw data; B: results after controlling for scores of general intelligence (measured by nonverbal matrix reasoning test); C: results after controlling for performance on all the general cognitive tests and language processing; D: results after controlling for performance on all the general cognitive tests, as well as language and arithmetic processing.

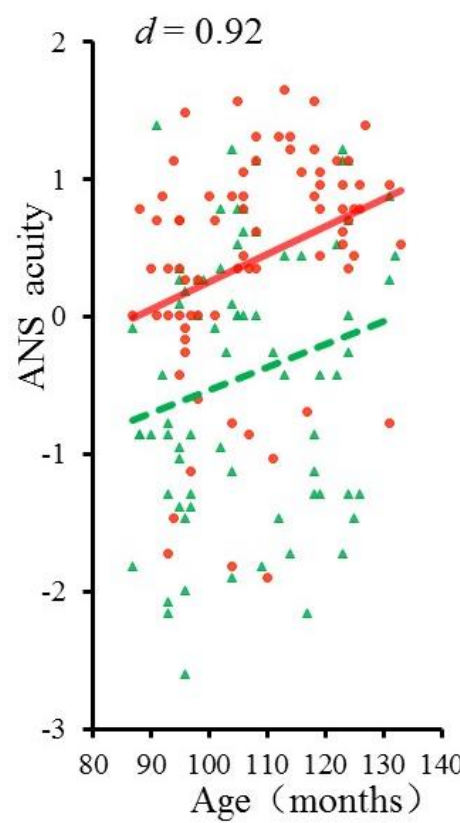

A

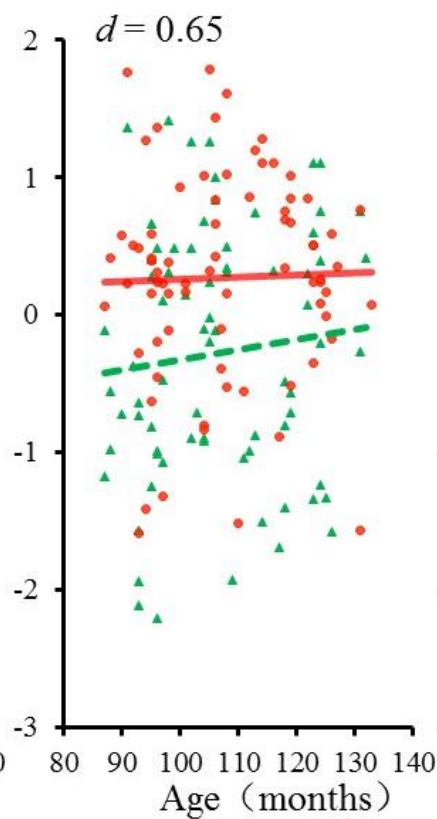

B

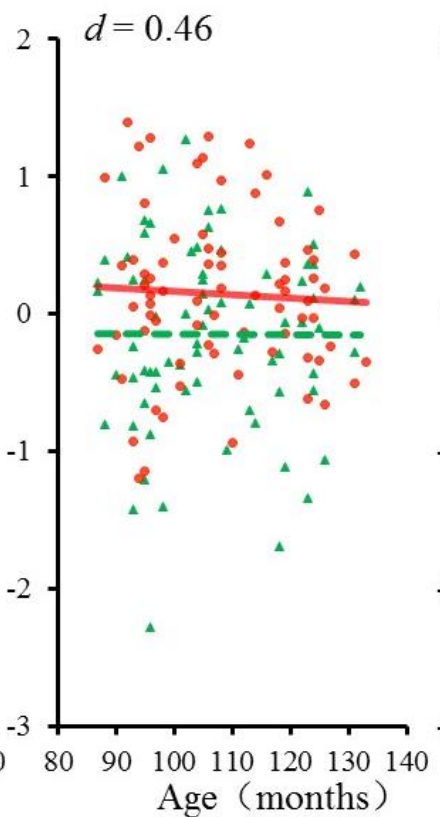

$\mathrm{C}$

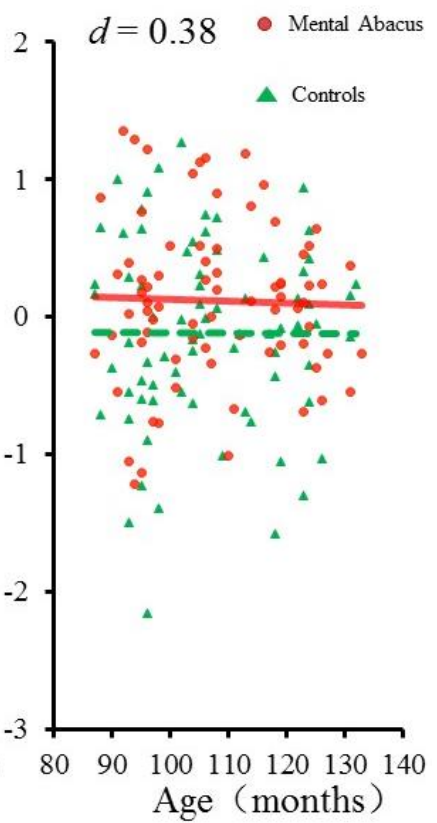

$\mathrm{D}$ 
Figure 5: Mediation model tested the effect of numerosity comparison (ACC) (M) between mental abacus scores (X) and subtraction (Y). ACC: accuracy.

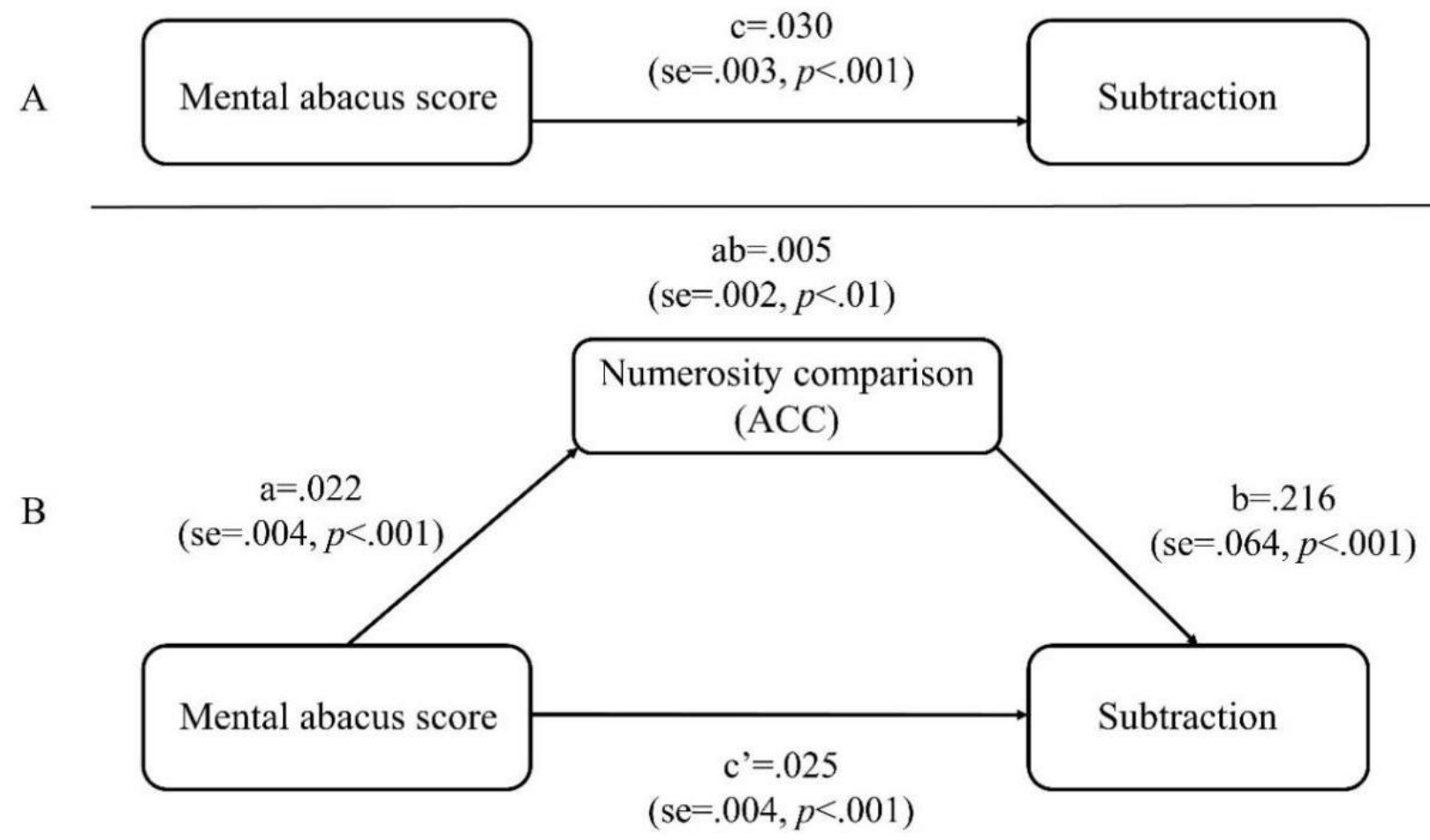

Note: Mediation analyses for the contributions of mental abacus ability to arithmetic ability. The top panel (A) is for the direct effect of mental abacus scores on arithmetic ability and the bottom panel (B) is for the mediation effect of non-symbolic number acuity (measured by accuracy on the numerosity comparison test) on the relationship between mental abacus scores and arithmetic ability. $\mathrm{c}=\mathrm{ab}+\mathrm{c}$. Values in the top panel (c) represent the direct effect of the original predictor. Values above the paths $(\mathrm{ab})$ represent indirect effects for non-symbolic number acuity on mental abacus scores and arithmetic ability. Values (c') below the paths represent residual direct effects (controlling for accuracy of numerosity comparison), which are the unmediated portions. Model used the Two-side test and the significance level was 0.001 . 
Appendix 1: Detailed illustration and examples from the mental abacus level test.

\begin{tabular}{|c|c|c|c|c|c|c|c|c|}
\hline \multirow[t]{2}{*}{ Level } & \multirow{2}{*}{$\begin{array}{l}\text { No. of } \\
\text { experts }\end{array}$} & \multirow{2}{*}{$\begin{array}{l}\text { No. of } \\
\text { operands }\end{array}$} & \multicolumn{4}{|c|}{ No. of digits in operands } & \multirow{2}{*}{$\begin{array}{l}\text { If with } \\
\text { decimals }\end{array}$} & \multirow[t]{2}{*}{ Examples } \\
\hline & & & 1 & 2 & 3 & 4 & & \\
\hline 10 & - & 3 & 3 & 0 & 0 & 0 & No & $5-3+9$ \\
\hline 9 & - & 4 & 3 & 1 & 0 & 0 & No & $7+6-3+64$ \\
\hline 8 & - & 5 & 3 & 2 & 0 & 0 & No & $40+84-5+2+7$ \\
\hline 7 & - & 6 & 3 & 2 & 2 & 0 & No & $9+70+81+247-3-8$ \\
\hline 6 & 15 & 7 & 3 & 3 & 1 & 0 & No & $69+258+47+25+2+8+1$ \\
\hline 5 & 17 & 7 & 2 & 3 & 2 & 0 & Yes & $0.71-0.59+1.48+0.05-0.01+0.14+6.93$ \\
\hline 4 & 10 & 8 & 2 & 3 & 2 & 1 & Yes & $708+5+4-19+31+42+4263+920$ \\
\hline 3 & 7 & 8 & 2 & 2 & 2 & 2 & Yes & $0.07+6.53+83.20-49.86+0.08+0.31+8.75+0.64$ \\
\hline 2 & 4 & 9 & 2 & 3 & 3 & 2 & Yes & $362+6473+39+8475-928+84-7-6+140+51$ \\
\hline 1 & 22 & 10 & 0 & 3 & 4 & 3 & Yes & $837+8271+93+9382-84+726-48-160+2615+759$ \\
\hline
\end{tabular}

Note: If problems contained decimals, their operands would all be decimals and the digits in the operands were calculated by summing the digits in integers and fractional parts of the decimals. 